\title{
Hysteroscopy versus transvaginal ultrasonography: finding the better modality for evaluation of postmenopausal bleeding
}

\author{
Mishika Bhoj ${ }^{1}$, Shakti Kumar Yadav ${ }^{2 *}$
}

\begin{abstract}
${ }^{1}$ Department of Obstetrics and Gynecology, Bombay Port Trust Hospital, Mumbai, Maharashtra, India
${ }^{2}$ Department of Pathology, North Delhi Municipal Corporation Medical College and Hindu Rao Hospital, New Delhi, India
\end{abstract}

Received: 02 February 2019

Accepted: 06 March 2019

\section{*Correspondence:}

Dr. Shakti Kumar Yadav,

E-mail: shaktipathology@gmail.com

Copyright: () the author(s), publisher and licensee Medip Academy. This is an open-access article distributed under the terms of the Creative Commons Attribution Non-Commercial License, which permits unrestricted non-commercial use, distribution, and reproduction in any medium, provided the original work is properly cited.

\begin{abstract}
Background: The most common cause of postmenopausal bleeding is benign pathology, but likelihood of malignancy must be promptly excluded. As excision of localized lesion has higher disease-free survival rate and lower morbidity as opposed to treatment for regional-stage disease. Commonly employed blind dilatation and curettage followed by histopathology is the current standard. A screening method with high sensitivity and specificity can help to prevent the invasive procedure and can also improve the accuracy of the biopsy. The objective of the present study was to study and compare the diagnostic accuracy of hysteroscopy and transvaginal ultrasonography in diagnosis of postmenopausal bleeding.

Methods: 80 female patients with complaints of postmenopausal bleeding were enrolled and followed up for a period of 10 months. Each patient underwent transvaginal ultrasonography and hysteroscopy followed by endometrial biopsy. Result were analyzed to find sensitivity, specificity, accuracy, PPV and NPV taking histopathological diagnosis as gold standard.

Results: Authors found that in 40 patients (50\%), the cause of post-menopausal bleeding was caused atrophic endometrium followed by endometrial hyperplasia seen in 14 patients (17.5\%). Hysteroscopy had higher overall sensitivity, specificity, NPV and accuracy as compared to transvaginal ultrasonography. Hysteroscopy was found to be highly accurate in diagnosing endometrial carcinoma (100\%) and endometrial polyps (100\%). However, both methods showed similar accuracy $(97.5 \%)$ in diagnosis of proliferative endometrium and hyperplasia.

Conclusions: Hysteroscopy is comparable to histopathology and superior to transvaginal sonography in the diagnosis of intrauterine causes for postmenopausal bleeding, it also offers the possibility of visualizing macroscopic or focal intra-uterine abnormalities.
\end{abstract}

Keywords: Endometrial carcinoma, Hysteroscopy, Postmenopausal bleeding, Transvaginal ultrasonography

\section{INTRODUCTION}

Menopause is defined as the permanent cessation of menstruation resulting from the loss of ovarian follicular activity. Natural menopause is recognized to have occurred after 12 consecutive months of amenorrhea, for which there is no other obvious pathological or physiological cause. ${ }^{1}$ The average age of menopause in Asian women is 46 years and with the increase in life expectancy, today a healthy 50 -year-old woman spends as much as $40 \%$ of her lifespan in postmenopausal state. During this prolonged period, women are vulnerable to various conditions, out of which one serious concern is postmenopausal bleeding (PMB). ${ }^{2}$ It is a warning sign 
and is a common indication of referral to gynaecology clinics due to fear of underlying malignancy. Other leading causes of PMB are exogenous estrogen, atrophic endometritis, atrophic vaginitis, endometrial hyperplasia, endometrial/cervical polyp, endometrial cancer and cervical cancer. ${ }^{3,4}$

In majority of the patients the cause for PMB is benign pathology, but possibility of malignancy must be promptly excluded. ${ }^{5}$ Endometrial carcinoma accounts for $10 \%$ cases of PMB and $90 \%$ of cases of endometrial carcinoma present with PMB. ${ }^{6}$ Treatment of localized lesion has higher associated disease-free survival and lower morbidity as opposed to treatment for regionalstage disease. ${ }^{7}$ The lifetime risk of developing endometrial cancer is $1.1 \%$ while the lifetime risk of dying of endometrial cancer is $0.4 \%$, reflecting the good prognosis of the condition with early diagnosis. ${ }^{8}$

Dilatation and curettage (D and C) under anaesthesia has long been the most common diagnostic tool in cases of abnormal uterine bleeding. ${ }^{9}$ While office endometrial biopsy is a sensitive and relatively inexpensive procedure for diagnosis of endometrial adenomatous hyperplasia and carcinoma, it is a poor test for diagnosing benign endometrial abnormalities such as atrophy, polyps and submucosal leiomyoma which are more common cause of bleeding. ${ }^{10-12}$ Being an invasive and costly procedure with associated surgical and anaesthetic complications, adequate indication is always needed. As it is a blind procedure, there are higher chances of missing focal endometrial lesions.

Several methods have been developed to assess uterine cavity, including transvaginal sonography (TVS), saline infusion sonography, and hysteroscopy (HS) each with its own advantages and disadvantages. Transvaginal sonography is a non-invasive and affordable method for indirect visualization of uterine pathology like uterine polyp and fibroid. It has allowed higher frequency probes to be employed, resulting in higher resolution and improved predictive ability yielding more detailed image of the uterus and thus facilitates endometrial thickness measurement with good patient acceptance. ${ }^{13,14}$ Many authors have suggested that TVS can also be used to detect many forms of endometrial pathology including cancer. $^{15,16}$ Considering that the risk of endometrial pathology increases with increase in endometrial thickness as measured by transvaginal ultrasound. ${ }^{17,18}$ The measurement of sonographic endometrial thickness makes it possible to separate women with postmenopausal bleeding into groups at low and high risk for endometrial malignancy: if the sonographic endometrial thickness is less than $5 \mathrm{~mm}$ the risk of endometrial malignancy is low, if it is $5 \mathrm{~mm}$ or more, the risk of endometrial malignancy is high. ${ }^{19}$

Hysteroscopy is a well-tolerated procedure which allows direct visualization as well as biopsy of the endometrium. ${ }^{20}$ Diagnostic hysteroscopy can detect focal lesions in the uterine cavity, and a preliminary histological diagnosis can be made. Since blind endometrial sampling techniques might fail to detect focal lesions, the 'see and treat' potential of hysteroscopy provides better patient satisfaction along with reduced hospital visits, making it procedure of choice, not only to visualize cervical canal and uterine cavity, but also for tissue biopsy and treatment of localized benign lesions. ${ }^{21}$ In present study, authors have evaluated these diagnostic methods for endometrial pathology for postmenopausal bleeding, that is measurement of endometrial thickness using transvaginal sonography and hysteroscopy with respect to histopathological diagnosis as gold standard.

\section{METHODS}

Present study was as prospective observational study conducted over a period of 10 months (February 2015 to December 2015). Sample size was calculated for sensitivity taking power of analysis at $80 \%$.

A total of 80 post-menopausal female patients presenting with complaints of bleeding per-vaginum were included in the study. After obtaining detailed informed consent for each patient, detailed personal and menstrual history was taken. A thorough general and systemic examination was done, along with abdominal, vaginal and rectal examination.

\section{Exclusion criteria}

- Patient with palpable abdominopelvic masses or suspected adnexal pathology were excluded from the study.

- Patients with vulval, vaginal or cervical lesions causing bleeding were also excluded.

Pap smear was done for all patients to rule out any concealed cervical pathology. Pre-operative investigations including complete blood count, Renal function test, Liver function test and urine analysis was done and fitness for anaesthesia was obtained.

Endometrial thickness (ET) was measured on TVS with a transvaginal ultrasound probe $(6.5 \mathrm{MHz})$ was done. The adnexal region was also scanned to exclude any adnexal mass. Results for TVS were expressed in 5 categories as: Normal cavity with proliferative endometrium, Endometrial hypertrophy (>3 mm for postmenopausal women), Endometrial atrophy (double layer $<4 \mathrm{~mm}$ ), Endometrial polyp (hyperechogenic lesion with a pedunculated attachment to the endometrium) and Submucosal myoma (lesion of mixed echogenicity disrupting the endometrial continuity). ${ }^{22,23}$ Clinical and sonographic evaluation was followed by diagnostic and/or therapeutic hysteroscopy. In each case, hysteroscopy with visualization of the uterine cavity was performed and biopsy was taken. On the basis of hysteroscopic findings the endometrium was categorized as: Proliferative, Atrophic Hyperplastic, Endometrial 
polyp and Endometrial carcinoma. Each diagnosis was analysed considering histopathology as gold standard. Appropriate statistical analysis was done to calculate sensitivity, specificity, positive predictive value, negative predictive value and accuracy of TVS and HS.

\section{RESULTS}

The age of the patients ranged from 45 to 74 years with mean age of 53.67 years (SD 6.59). Age of menopause, duration since menopause, parity, comorbidities, body mass index of study group are shown in Table 1.

Table 1: Clinical details of the study group.

\begin{tabular}{|c|c|c|}
\hline Attribute & No. & Percentage \\
\hline \multicolumn{3}{|l|}{ Age group (years) } \\
\hline$<45$ & - & - \\
\hline $45-54$ & 52 & 65 \\
\hline $55-64$ & 22 & 27.5 \\
\hline $65-74$ & 6 & 7.5 \\
\hline \multicolumn{3}{|c|}{ Age of menopause (years) } \\
\hline$<45$ & 22 & 27.5 \\
\hline $45-49$ & 34 & 42.5 \\
\hline $50-54$ & 22 & 27.5 \\
\hline$\geq 55$ & 2 & 2.5 \\
\hline \multicolumn{3}{|c|}{ Duration since menopause (in years) } \\
\hline$<3$ & 20 & 25 \\
\hline $3-9$ & 36 & 45 \\
\hline $10-19$ & 20 & 25 \\
\hline$\geq 20$ & 4 & 5 \\
\hline \multicolumn{3}{|l|}{ Parity } \\
\hline Primi & 2 & 2.5 \\
\hline Multi & 68 & 85 \\
\hline Grand multipara & 10 & 12.5 \\
\hline Nulli & - & - \\
\hline \multicolumn{3}{|l|}{ Comorbidity } \\
\hline DM & 20 & 25 \\
\hline HTN & 42 & 52.5 \\
\hline Hypothyroid & 6 & 7.5 \\
\hline Hyperlipidemia & 20 & 25 \\
\hline Others & 10 & 12.5 \\
\hline \multicolumn{3}{|l|}{ BMI } \\
\hline <18.5 (Underweight) & 4 & 5 \\
\hline 18.5-24.9 (Healthy) & 22 & 27.5 \\
\hline 25-29.9 (Over weight) & 30 & 37.5 \\
\hline$\geq 30($ Obese $)$ & 24 & 30 \\
\hline \multicolumn{3}{|c|}{ Endometrial thickness (TVS) } \\
\hline$<5$ & 40 & 50 \\
\hline $5-10$ & 20 & 22.5 \\
\hline $11-15$ & 18 & 22.5 \\
\hline$>15$ & 4 & 5 \\
\hline \multicolumn{3}{|l|}{ Causes of PMB } \\
\hline Atrophic & 40 & 50 \\
\hline $\mathrm{Ca}$ endometrium & 8 & 10 \\
\hline Hyperplasia & 14 & 17.5 \\
\hline Polyp & 12 & 15 \\
\hline Proliferative & 6 & 7.5 \\
\hline
\end{tabular}

The endometrial thickness measured on TVS was $<5 \mathrm{~mm}$ in 40 patients $(50 \%), 5-10 \mathrm{~mm}$ in 20 patients $(25 \%), 11$ $15 \mathrm{~mm}$ in 18 patients $(22.5 \%)$ and $>15 \mathrm{~mm}$ in 4 patients $(5 \%)$.

Authors found that in 40 patients (50\%), post-menopausal bleeding was caused by atrophic endometrium being the commonest cause while second commonest cause was endometrial hyperplasia seen in 14 patients (17.5\%) followed by then is polyp (15\%), proliferative endometrium $(7.5 \%)$.

Although, endometrial carcinoma is the cause of postmenopausal bleeding in $10 \%$ of cases on histopathology (Table 2).

Table 2: Comparison of finding on TVS and HS with histopathological diagnosis.

\begin{tabular}{|l|l|l|l|}
\hline Diagnosis & Histopathology & TVS & Hysteroscopy \\
\hline Atrophic & 40 & 38 & 40 \\
& $(50)$ & $(47.5)$ & $(50)$ \\
\hline $\begin{array}{l}\text { Endometrial } \\
\text { carcinoma }\end{array}$ & 8 & 4 & 8 \\
\hline Hyperplasia & 14 & $(5)$ & $(10)$ \\
\hline Polyp & $(17.5)$ & 16 & 12 \\
\hline Proliferative & 6 & $(20)$ & $(15)$ \\
\hline & $(7.5)$ & 14 & 12 \\
\hline
\end{tabular}

Diagnostic accuracy of TVS and HS for diagnosis of each category was determined with respect to the histopathological diagnosis (Table 3).

\section{DISCUSSION}

Post-menopausal bleeding accounts for 5\% of all gynaecologic office visits.

While it is not always a symptom of cancer, the exclusion of endometrial hyperplasia and carcinoma is the key issue in the evaluation of patients with postmenopausal bleeding. ${ }^{24}$

Even a single episode of PMB must be evaluated. Incidence of endometrial carcinoma was higher in older females, while non-malignant causes of postmenopausal bleeding like atrophic endometrium, proliferative endometrium were more among younger females. In present study, endometrial carcinoma was found in $10 \%$ of patients.

Similar to our findings, Tandulwadkar S et al, calculated incidence of endometrium cancer at $13.3 \%$, while incidence of atrophic endometrium was $66.6 \%$ and hyperplastic endometrium was $6.6 \% .^{25}$

Various studies have compared the role of TVS and HS in diagnosis of uterine lesions. Vitner et al, found higher 
sensitivity and specificity for HS in diagnosis of uterine myoma. ${ }^{26,27}$ They did not found any statistical difference for diagnosis of polyp between the two techniques.
Ali Babacan et al, found that HS has better sensitivity and specificity in diagnosis of polyp than TVS. This was in concordance with present study. ${ }^{27}$

Table 3: Comparison of sensitivity of TVS and HS with histopathological diagnosis.

\begin{tabular}{|c|c|c|c|c|c|c|}
\hline Pathological diagnosis & Diagnostic modality & Sensitivity & Specificity & PPV & NPV & Accuracy \\
\hline \multirow[t]{2}{*}{ Over all } & TVS & 94.2 & 95.6 & 94.12 & 95.6 & 95 \\
\hline & HS & 100 & 95.8 & 94 & 100 & 97.5 \\
\hline \multirow[t]{2}{*}{ Atrophic } & TVS & 95 & 100 & 100 & 95.2 & 97.5 \\
\hline & $\mathrm{HS}$ & 100 & 100 & 100 & 100 & 100 \\
\hline \multirow[t]{2}{*}{ Endometrial carcinoma } & TVS & 50 & 100 & 100 & 94.7 & 95 \\
\hline & HS & 100 & 100 & 100 & 100 & 100 \\
\hline \multirow{2}{*}{ Hyperplasia } & TVS & 100 & 96.9 & 87.5 & 100 & 97.5 \\
\hline & $\mathrm{HS}$ & 85.7 & 100 & 100 & 97.6 & 97.5 \\
\hline \multirow{2}{*}{ Polyp } & TVS & 100 & 97.06 & 85.71 & 100 & 97.5 \\
\hline & HS & 100 & 100 & 100 & 100 & 100 \\
\hline \multirow[t]{2}{*}{ Proliferative } & TVS & 100 & 97.3 & 75 & 100 & 97.5 \\
\hline & HS & 100 & 97.3 & 75 & 100 & 97.5 \\
\hline
\end{tabular}

Although transvaginal ultrasound does not need general anaesthesia and gives immediate information, in present study it was found to have low sensitivity (50\%) for detection of endometrial cancer. Only 4 out of 8 cases of endometrial cancer were detected by TVS. In present study authors found that hysteroscopy was a superior method than transvaginal sonography, with higher sensitivity, specificity, positive predictive value, negative predictive value and accuracy in diagnosing the cause of postmenopausal bleeding. In all the 80 study cases hysteroscopy was done with no failure. The method success rate of $100 \%$ in this study indicates simplicity of the procedure. This corresponds to the results of study by of Van Dongen et al (96.9\%), Nikolaou et al (96\%) and Dinić et al $(98 \%){ }^{28,29,30}$ Complication of cervical false passage was seen in just 1 case due to cervical stenosis and difficult dilatation which shows the safety of the procedure in trained hands. According to present study, Hysteroscopy is comparable to histopathology for the diagnosis of intrauterine pathologies causing postmenopausal bleeding, with high overall sensitivity (100\%), specificity (95.8\%), PPV (94\%) and NPV $(100 \%)$ These results are in accordance with the findings of Tandulwarkar S et al, Fadi Alfhaily et al, Van Dongen et al, Guida $\mathrm{M}$ et al and Sousa et al. ${ }^{25,28,31-33}$ However, Ali Badacan et al found lower sensitivity (82\%) specificity $(84.9 \%)$ than present study. This could be because of the difference in the sample size and performer's skills. ${ }^{27}$ The results of these studies are compared in Table 4. As $10 \%$ of cases of post-menopausal bleeding had endometrial carcinoma in present study, high sensitivity of hysteroscopy justifies its use in all post-menopausal bleeding cases.

Table 4 Comparison of TVS results in present study with previous studies.

\begin{tabular}{|c|c|c|c|c|}
\hline Authors & Sensitivity (\%) & Specificity (\%) & PPV $(\%)$ & NPV $(\%)$ \\
\hline Present study & 94.12 & 95.6 & 94.12 & 95.6 \\
\hline Badacan $\mathrm{A}$ et $\mathrm{al}^{27}$ & 92.9 & 41.4 & 78.3 & 72.0 \\
\hline Tandulwarkar S et $\mathrm{al}^{25}$ & 100 & 100 & - & - \\
\hline Alfhaily $\mathrm{F}$ et $\mathrm{al}^{31}$ & 90 & 94 & 92 & 96 \\
\hline Dongen $\mathrm{V}$ et $\mathrm{al}^{28}$ & 96 & 90 & - & - \\
\hline Guida $\mathrm{M}$ et al ${ }^{32}$ & 90 & 94 & 92 & 96 \\
\hline Sousa R et $\mathrm{al}^{33}$ & 88.9 & 98.3 & 88.9 & 98.3 \\
\hline
\end{tabular}

Hysteroscopy should be avoided in frank cases of endometrial carcinoma due to risk of peritoneal spillage of malignant cells. Decision for Hysteroscopy should be carefully evaluated in all the doubtful cases considering the risk of peritoneal spread during the procedure. In present study, all the suspected patient had tubal ligation 
done, thus reducing the risk of peritoneal spread. With adequate tools and a skilled operator, disadvantages can be minimized. In some cases, the hysteroscopic visual diagnosis may not correlate with the final histologic diagnosis: it is prudent to do endometrial sampling in all such doubtful cases. Targeted biopsy is clearly the most accurate procedure.

Authors have compared the hysteroscopic findings of present study with previous study in Table 5 .

Table 5: Comparison of hysteroscopic finding in present and previous studies.

\begin{tabular}{|c|c|c|c|c|c|}
\hline Authors & Uterine pathology & Sensitivity & Specificity & PPV & NPV \\
\hline \multirow{3}{*}{ Present study } & Polyp & 100 & 100 & 100 & 100 \\
\hline & Hyperplasia & 85.7 & 100 & 100 & 97.6 \\
\hline & Atrophy & 100 & 100 & 100 & 100 \\
\hline \multirow{3}{*}{ Dinić $\mathrm{T}$ et $\mathrm{al}^{30}$} & Polyp & 91.5 & 100 & 100 & 96 \\
\hline & Hyperplasia & 100 & 96 & 50 & 100 \\
\hline & Atrophy & 100 & 98 & 89 & 100 \\
\hline \multirow{2}{*}{ Babacan A et $\mathrm{al}^{27}$} & Polyp & 82 & 84.9 & 82.6 & 84.3 \\
\hline & Atrophy & 66.6 & 99.6 & 94.7 & 96.6 \\
\hline Angioni $\mathrm{S}$ et $\mathrm{al}^{34}$ & Polyp & 100 & 97 & - & - \\
\hline Clark et al $^{35}$ & $\mathrm{Ca}^{2+}$ endometrium & 86.4 & 99.2 & - & - \\
\hline
\end{tabular}

In present study, 12 cases were diagnosed as polyp on hysteroscopy and successful polypectomy was done in the same sitting. This could have been missed by blind sampling technique leading to persistent complain of bleeding and would have been ended up with hysterectomy.

Thus, hysteroscopy have successfully avoided hysterectomy and risk related to such major surgery and anaesthesia in these population with associated comorbidities. 8 cases were suspected to have $\mathrm{Ca}^{2+}$ endometrium which were later confirmed on histopathological examination on the endometrial sample which was collected under hysteroscopic guidance and Hysterectomy was done in these cases.

Hysterectomy was also done for 4 histopathologically confirmed cases of complex Hyperplasia with atypia. 40 out of 80 cases that is $50 \%$ had atrophic endometrium, 6 cases with Hyperplasia without atypia and 06 cases with proliferative endometrium on Hysteroscopy were managed medically. 3 of present patients had submucosal fibroid which was, detected along with atrophy endometrium. Hysteroscopic resection could be done of this submucosal myomas using hysteroscopic resectoscope.

Sample size was limiting factor in the present study. However, a larger prospective study with higher sample size may be undertaken to compare the TVS and HS and other techniques in diagnosis of uterine pathology.

\section{CONCLUSION}

In conclusion, hysteroscopy is comparable to histopathology and superior to transvaginal sonography in the diagnosis of intrauterine causes for postmenopausal bleeding, it also offers the possibility of visualizing macroscopic or focal intra-uterine abnormalities. Simultaneous management of the focal lesions or biopsy under vision can be taken from the focal lesions which could be missed by blind sampling technique.

Diagnostic hysteroscopy is useful both in predicting disease and excluding a non-disease state. Hysteroscopy is safe and effective diagnostic method in postmenopausal bleeding as there was very low complication rate and high diagnostic accuracy. Hysteroscopy is not a replacement for tissue biopsy, it's prudent to do histopathology in all doubtful cases as visual findings on hysteroscopy may at times fail to correlate with the histopathology findings. Targeted biopsy under hysteroscopic vision is the best way to evaluate a case of postmenopausal bleeding.

Funding: No funding sources

Conflict of interest: None declared

Ethical approval: The study was approved by the Institutional Ethics Committee

\section{REFERENCES}

1. World Health Organization. Research on the menopause in the 1990s: report of a WHO scientific group.

2. Moodley M, Roberts C. Clinical pathway for the evaluation of postmenopausal bleeding with an emphasis on endometrial cancer detection. J Obstet Gynaecol. 2004;24(7):736-41.

3. Hacker NF, Moore JG. Essentials of obstetrics and gynaecology, $3^{\text {rd }}$ ed. Philadelphia: WB saunders, 1998:635. 
4. Pacheco JC, Kempers RD. Etiology of postmenopausal bleeding. Obstet Gynecol.1968;32(1):40-6.

5. Osmers RG, Kuhn W. Endometrial cancer screening. Current Op Obstet Gynecol. 1994;6(1):75-9.

6. Dutch Society of Obstetrics and Gynecology (NVOG). Diagnostics in abnormal vaginal blood loss in the postmenopausal period; 2003.

7. Landis SH, Murray T, Bolden S, Wingo PA. Cancer statistics, 1999. CA: A Cancer J Clinic. 1999;49(1):8-31.

8. American College of Obstetricians and Gynecologists. ACOG Committee Opinion No. 426: The role of transvaginal ultrasonography in the evaluation of postmenopausal bleeding. Obstet Gynecol. 2009;113(2 Pt 1):462.

9. Grimes DA. Diagnostic dilatation and curettage: a reappraisal. Am J Obstet Gynecol. 1982;142:1-6.

10. Büyük E, Durmuşoĝlu F, Erenus M, Karakoç B. Endometrial disease diagnosed by transvaginal ultrasound and dilatation and curettage. Acta Obstetricia et Gynecologica Scandinavica. 1999;78(5):419-22.

11. Karlsson B, Granberg S, Hellberg P, Wikland M. Comparative study of transvaginal sonography and hysteroscopy for the detection of pathologic endometrial lesions in women with postmenopausal bleeding. J Ultrasound Med. 1994;13(10):757-62.

12. O'connell LP, Fries MH, Zeringue E, Brehm W. Triage of abnormal postmenopausal bleeding: a comparison of endometrial biopsy and transvaginal sonohysterography versus fractional curettage with hysteroscopy. Am J Obstet Gynecol. 1998;178(5):956-61.

13. Mendelson EB, Bohm-Velez M, Joseph N, Neiman H. Endometrial abnormalities: evaluation with transvaginal sonography. Am J Roentgenol. 1988;150(1):139-42.

14. Osmers R, Volksen M, Schauer A. Vaginosonography for early detection of endometrial carcinoma? Lancet 1990 335/8705 (1569-1571). Maturitas. 1991;13(1):86.

15. Fleischer AC, Kalemeris GC, Machin JE, Entman SS, James Jr AE. Sonographic depiction of normal and abnormal endometrium with histopathologic correlation. J Ultrasound Med. 1986;5(8):445-52.

16. Nasri M, Coast G. Correlation of ultrasound findings and endometrial histopathology in postmenopausal women. BJOG: An International J Obstet Gynaecol. 1989;96(11):1333-8.

17. Karlsson B, Granberg S, Wikland M, Ylostalo P, Torvid K, Marsal K, et al. Transvaginal ultrasonography of the endometrium in women with postmenopausal bleeding: a Nordic multicenter study. Am J Obstet Gynecol. 1995;172(5):1488-94.

18. Smith-Bindman R, Kerlikowske K, Feldstein VA, Subak L, Scheidler J, Segal M et al. Endovaginal ultrasound to exclude endometrial cancer and other endometrial abnormalities. Jama. 1998;280(17):1510-7.
19. Weber G, Mere E, Bahlmanw E, Riisch B. Evaluation of different transvaginal sonographic diagnostic parameters in women with postmenopausal bleeding. Ultrasound Obstet Gynecol. 1998;12(4):265-70.

20. Gimpelson RJ, Rappold HO. A comparative study between panoramic hysteroscopy with directed biopsies and dilatation and curettage: a review of 276 cases. Am J of Obstet Gynecol. 1988;158(3):489-92.

21. Widrich T, Bradley LD, Mitchinson AR, Collins RL. Comparison of saline infusion sonography with office hysteroscopy for the evaluation of the endometrium. Am J of Obstet Gynecol. 1996;174(4):1327-34.

22. Osmers R, Puchta J, Suren A. Pathological findings of the postmenopausal endometrium. Ultrasound Uterus. 1995:31-44.

23. Parsons AK, Lense JJ. Sonohysterography for endometrial abnormalities: preliminary results. J Clinic Ultrasound. 1993;21(2):87-95.

24. Hsu C-Y, Chen C-P, Wang K-L. Assessment of postmenopausal bleeding. Int J Gerontol. 2008;2:559.

25. Tandulwadkar S, Deshmukh P, Lodha P, Agarwal B. Hysteroscopy in postmenopausal bleeding. Journal Gynecol Endoscopy and Surg. 2009;1(2):89.

26. Vitner D, Filmer S, Goldstein I, Khatib N, Weiner Z. A comparison between ultrasonography and hysteroscopy in the diagnosis of uterine pathology. European J Obstet Gynecol Reproduct Biol. 2013;171(1):143-5.

27. Babacan A, Gun I, Kizilaslan C, Ozden O, Muhcu M, Mungen E, Atay V. Comparison of transvaginal ultrasonography and hysteroscopy in the diagnosis of uterine pathologies. Int $\mathrm{J}$ Clinical Experiment Med. 2014;7(3):764.

28. Van Dongen H, De Kroon CD, Jacobi CE, Trimbos JB, Jansen FW. Diagnostic hysteroscopy in abnormal uterine bleeding: a systematic review and metaanalysis. BJOG: Int J Obstet Gynaecol. 2007;114(6):664-75.

29. Nikolaou D, Salman G, Richardson R. Operative hysteroscopy in the outpatient setting: its role within a gynaecology service. Gynecol Surg. 2009;6(1):214.

30. Dinić T, Pop S, Kopitović V, Antić V, Stamenović S, Mitić D, et al. Role of Hysteroscopy in Evaluation of Patients with Abnormal Uterine Bleeding. Acta Facultatis Medicae Naissensis. 2011;28(3).

31. Alfhaily F, Ewies AA. The first-line investigation of postmenopausal bleeding: transvaginal ultrasound scanning and endometrial biopsy may be enough. Int J Gynecol Cancer. 2009;19(5):892-5.

32. Guida M, Bramante S, Acunzo G, Lavitola G, Sparice S, Cerrota G, Nappi C. Evaluation of endometrial carcinoma using hysteroscopy and transvaginal echography. Tumori. 2003;89(4):253-4.

33. Sousa R, Silvestre M, Sousa LA, Falcão F, Dias I, Silva T, Oliveira CD, Oliveira HM. Transvaginal ultrasonography and hysteroscopy in 
postmenopausal bleeding: a prospective study. Acta Obstet et Gynecol Scandinavica. 2001;80(9):856-62.

34. Angioni S, Loddo A, Milano F, Piras B, Minerba L, Melis GB. Detection of benign intracavitary lesions in postmenopausal women with abnormal uterine bleeding: a prospective comparative study on outpatient hysteroscopy and blind biopsy. J Minimally Invasive Gynecol. 2008 ;15(1):87-91.

35. Clark TJ, Voit D, Gupta JK, Hyde C, Song F, Khan KS. Accuracy of hysteroscopy in the diagnosis of endometrial cancer and hyperplasia: a systematic quantitative review. Jama. 2002;288(13):1610-21.

Cite this article as: Bhoj M, Yadav SK.

Hysteroscopy versus transvaginal ultrasonography: finding the better modality for evaluation of postmenopausal bleeding. Int J Reprod Contracept Obstet Gynecol 2019;8:1568-74. 